\title{
The Potsdam Parallel Ice Sheet Model (PISM-PIK) - Part 2: Dynamic equilibrium simulation of the Antarctic ice sheet
}

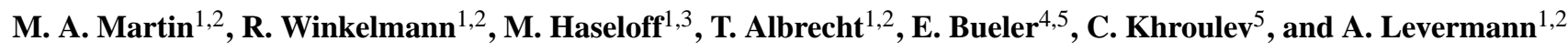 \\ ${ }^{1}$ Earth System Analysis, Potsdam Institute for Climate Impact Research, Potsdam, Germany \\ ${ }^{2}$ Institute of Physics, Potsdam University, Potsdam, Germany \\ ${ }^{3}$ Department of Physics, Humboldt-University, Berlin, Germany \\ ${ }^{4}$ Department of Mathematics and Statistics, University of Alaska, Fairbanks, USA \\ ${ }^{5}$ Geophysical Institute, University of Alaska, Fairbanks, USA
}

Received: 15 July 2010 - Published in The Cryosphere Discuss.: 18 August 2010

Revised: 5 July 2011 - Accepted: 22 August 2011 - Published: 14 September 2011

\begin{abstract}
We present a dynamic equilibrium simulation of the ice sheet-shelf system on Antarctica with the Potsdam Parallel Ice Sheet Model (PISM-PIK). The simulation is initialized with present-day conditions for bed topography and ice thickness and then run to steady state with constant present-day surface mass balance. Surface temperature and sub-shelf basal melt distribution are parameterized. Grounding lines and calving fronts are free to evolve, and their modeled equilibrium state is compared to observational data. A physically-motivated calving law based on horizontal spreading rates allows for realistic calving fronts for various types of shelves. Steady-state dynamics including surface velocity and ice flux are analyzed for whole Antarctica and the Ronne-Filchner and Ross ice shelf areas in particular. The results show that the different flow regimes in sheet and shelves, and the transition zone between them, are captured reasonably well, supporting the approach of superposition of SIA and SSA for the representation of fast motion of grounded ice. This approach also leads to a natural emergence of sliding-dominated flow in stream-like features in this new 3-D marine ice sheet model.
\end{abstract}

\section{Introduction}

One of the most severe shortcomings of the Fourth Assessment Report (AR4) of the Intergovernmental Panel on Climate Change (IPCC) was the lack of a process-based assess-

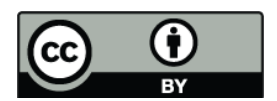

Correspondence to: A. Levermann (anders.levermann@pik-potsdam.de) ment of future sea-level rise for the 21st century and beyond. While the direct effect of oceanic warming and related thermal expansion are captured with some uncertainty by state-of-the-art climate models, modeling studies for fast processes in land ice continue to be sparse. Observations, however, support the importance of modeling these ice flow processes. On the Antarctic Peninsula, for example, an acceleration of ice flow across the grounding line has been observed in response to ice-shelf disintegration (e.g., Pritchard et al., 2009; Rott et al., 2011). The fast ice flow regimes in the vicinity of the grounding line as well as ice-shelf dynamics constitute two of the largest challenges in ice sheet modeling.

Here we present a simulation for the Antarctic sheet-shelf system with the Potsdam Parallel Ice Sheet Model (PISMPIK) with a special focus on both ice shelf dynamics and the transition zone between grounded and floating ice.

Our modeling approach is based on the Shallow Ice Approximation (SIA) and the Shallow Shelf Approximation (SSA) which make use of the fact that ice thickness is small compared to relevant horizontal scales and reduce the full Stokes problem by scaling the equations with the small depth-to-width ratio of ice sheets. There are several models combining the stress balance from the SIA for grounded ice with the SSA for ice shelves in simulations of the Antarctic Sheet-Shelf system (e.g., Huybrechts, 1990; Hulbe and MacAyeal, 1999; Ritz et al., 2001; Pollard and Deconto, 2009). Based on the Parallel Ice Sheet Model (PISM, Bueler and Brown, 2009), the Potsdam Parallel Ice Sheet Model (PISM-PIK) introduced additional components which are necessary to simulate Antarctic ice flow, in particular ice shelf dynamics (Winkelmann et al., 2011). These include a stress boundary condition for the entire ice

Published by Copernicus Publications on behalf of the European Geosciences Union. 
margin, a parameterization for subgrid-scale motion of iceshelf calving-fronts (Albrecht et al., 2011) and a new calvingrate law which is presented in Levermann et al. (2011).

In this paper we first describe the set-up for a dynamic equilibrium simulation for Antarctica in Sect. 2. Section 3 presents the performance of PISM-PIK under present-day conditions in this simulation and summarizes and discusses it in comparison with observations. A conclusion is given in Sect. 4.

\section{Model setup for the dynamic equilibrium simulation}

For our dynamic equilibrium simulation the following model setup is used: the model domain is discretized on a $301 \times 301$ horizontal grid with $19.98 \mathrm{~km}$ spacing. The vertical grid has 51 levels within a domain extending $5000 \mathrm{~m}$ above the bed elevation. The vertical spacing ranges from $26.5 \mathrm{~m}$ in the lowest layer to $173.5 \mathrm{~m}$ spacing at the surface of the thickest ice. The temperature is stored on this unequally-spaced grid, but the equation of conservation of energy is solved on a vertical grid with uniform spacing of $26 \mathrm{~m}$. A thin bedrock layer of $265 \mathrm{~m}$ with $26.5 \mathrm{~m}$ spacing was used, following the reasons given in Bueler and Brown (2009).

The input fields for topography and initial ice thickness are regridded from the present-day ALBMAP v1 data (Le Brocq et al., 2010) available on the SeaRISE (2011) project website. These data update the earlier BEDMAP (Lythe et al., 2001). Surface mass balance is adopted from Van de Berg et al. (2006), and geothermal flux is based on the model of Shapiro amd Ritzwoller (2004). Throughout the equilibrium simulation surface mass balance, geothermal flux and bed topography are held fixed. Notation for this paper is in Table A1.

Similar to Huybrechts (1993) and Pollard and Deconto (2009), the surface temperature field is parameterized as a function of latitude and surface elevation:

$T_{\mathrm{S}}=273.15+30-0.0075 h-0.6878|\Phi|$

with latitude $|\Phi|$ in ${ }^{\circ} S$; temperature is given in Kelvin. This parameterization reproduces the observed temperatures for the present-day surface elevation (Comiso, 2000; Van den Broeke, 2008), particularly on the ice shelves.

This surface temperature field serves as a Dirichlet boundary condition to the equation of conservation of energy (Eq. 3 in Winkelmann et al., 2011) which governs thermodynamics within the ice body. This has not changed compared to PISM and is described in detail in Bueler and Brown (2009); Bueler et al. (2007).

At the base of the ice shelf we provide boundary conditions both for the temperature field as well as a sink/source term for the mass continuity equation (Eq. 1 in Winkelmann et al., 2011) which incorporates basal melting and refreezing. For the temperature evolution within the ice we define the boundary as ice which is at pressure melting temperature. Hence the pressure-melting temperature $T_{\mathrm{pm}}$ is applied as a Dirichlet boundary condition to the conservation of energy equation:

$T_{\mathrm{pm}}=273.15+\beta_{\mathrm{CC}} z_{\mathrm{b}}$

with $z_{\mathrm{b}}$ as the elevation (generally negative) of the base of the ice shelf and with Clausius-Clapeyron gradient $\beta_{\mathrm{CC}}$. Concerning the basal melting and refreezing a warm and saline ocean is the determining factor: a mass flux $S$ from shelf to ocean

$S=Q_{\text {heat }} /\left(L_{\mathrm{i}} \rho_{\mathrm{i}}\right)$

where $L_{\mathrm{i}}$ is the latent heat capacity of ice and $\rho_{\mathrm{i}}$ ice density, is computed from a heat flux $Q_{\text {heat }}$. This heat flux is determined following Beckmann and Goosse (2003) using a virtual temperature $T_{\mathrm{f}}$, which is the freezing temperature of ocean water at the depth $z_{\mathrm{b}}$ below the ice shelf

$T_{\mathrm{f}}=273.15+0.0939-0.057 S_{\mathrm{o}}+7.64 \times 10^{-4} z_{\mathrm{b}}$.

Here $S_{\mathrm{o}}$ is the salinity of the ocean with a value of $35 \mathrm{psu}$. The transition from the base of the shelf with a salinity close to zero (Oerter et al., 1992) to the ocean water of full salinity occurs in the oceanic mixed layer which we cannot resolve in our approach. The resulting heat flux between ocean and ice, representing the melting effect of the ocean through both temperature and salt, is computed from

$Q_{\text {heat }}=\rho_{\mathrm{o}} c_{p_{\mathrm{o}}} \gamma_{\mathrm{T}} F_{\text {melt }}\left(T_{\mathrm{o}}-T_{\mathrm{f}}\right)$,

with $\rho_{\mathrm{o}}$ density of ocean water and $c_{p_{\mathrm{o}}}$ specific heat capacity of the ocean mixed layer. For the present simulation $T_{\mathrm{O}}$ is set to a constant value of $-1.7^{\circ} \mathrm{C}$ (see Table A1), based on the NCEP reanalysis value for the Ross Ice Shelf given in Beckmann and Goosse (2003). Here $\gamma_{T}$ is the thermal exchange velocity and $F_{\text {melt }}$ a model parameter. While we adopt a value of $\gamma=10^{-4}$ (Holland and Jenkins, 1999; Hellmer and Olbers, 1989) the tuning process showed that the introduction of the model parameter $F_{\text {melt }}$, with a value of $F_{\text {melt }}=5 \times 10^{-3}$ was necessary in order to match the present position of the grounding line especially in West Antarctica. This results in a low magnitude of the melt rate shown in Fig. 1. The spatial pattern of subshelf melt rates however depends on the shelf bottom temperature which is closely related to the shelf thickness, which is supported by Beckmann and Goosse (2003).

As detailed in Winkelmann et al. (2011), Sect. 2.2, ice velocities are calculated in PISM-PIK as the sum of the SIA velocities and the SSA velocities with basal resistance that are computed everywhere in the grounded ice. In fact, for grounded ice the SSA velocity is interpreted as the basal sliding velocity $\boldsymbol{v}_{\mathrm{b}}$ (Bueler and Brown, 2009). This provides a smooth transition both from non-sliding ice which is frozen to the bedrock (with negligibly small $v_{\mathrm{b}}$ ) to faster flowing ice 

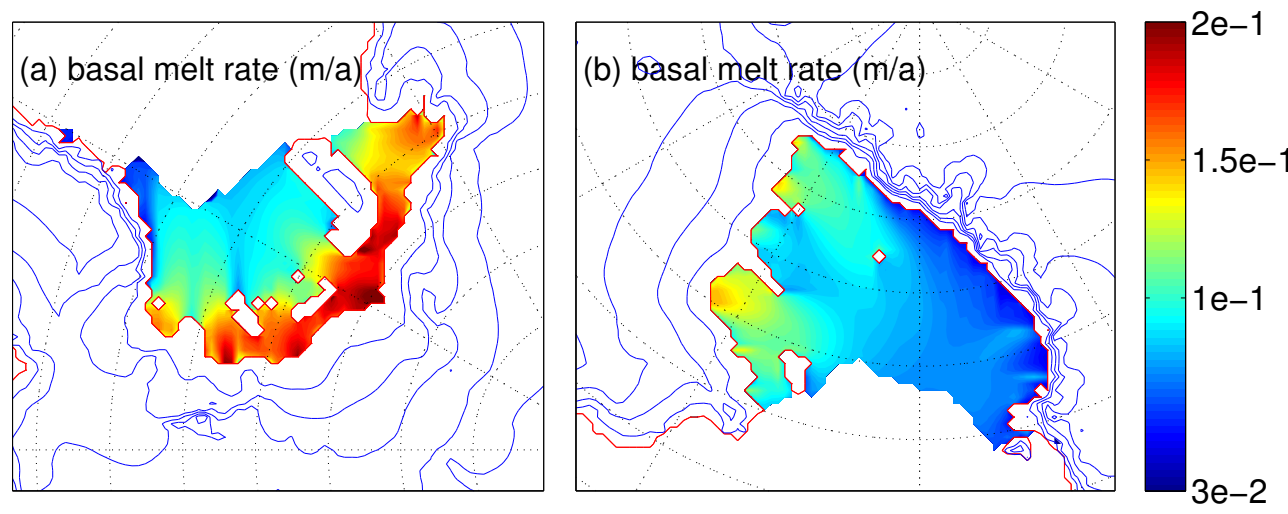

Fig. 1. Basal melt rate for (a) Ronne-Filchner and (b) Ross Ice Shelves, as given by Eq. (3). The parameterization used here leads to melt rates which depend on the shelf thickness and are highest near the grounding lines (red). Blue lines are contours of surface elevation.

where noteworthy sliding occurs, and from rapidly-sliding ice across the grounding line to an ice shelf. The reasoning supporting this approach and its placement within the family of shallow and hybrid models is given in the description paper of PISM-PIK, Winkelmann et al. (2011). In contrast to PISM we do not use a weighting function to combine the two velocity contributions, but simply add them. Features that we call "streams" in the context of this simulation are defined diagnostically as regions where SSA (i.e., basal) velocities $\boldsymbol{v}_{\mathrm{b}}$ are larger than SIA velocities,

$\boldsymbol{v}_{\mathrm{b}}>\overline{\boldsymbol{v}}-\boldsymbol{v}_{\mathrm{b}}$

with $\overline{\boldsymbol{v}}$ the vertical average of the full velocity $\boldsymbol{v}_{\mathrm{SIA}}+\boldsymbol{v}_{\mathrm{SSA}}$. Figure 2 shows the velocity patterns emerging from the superposition of SIA and SSA velocities for an example cut through the sheet-shelf transition zone of the Lambert Glacier and the Amery Ice Shelf in the simulation. This example illustrates how the two velocity contributions supersede each other in the sheet and in the ice shelf except in a transition region in the upper part of a stream-like flow pattern. The onset of this transition region can be found where the SSA velocity rises above the SIA velocity on grounded ice, i.e., where the red curve crosses the blue curve in Fig. 2.

This observed smooth transition from quasi no-slip in the interior of the ice sheet to sliding is a result of the solution of the free boundary problem analyzed in Schoof (2006b), in which both locations of sliding and the sliding velocity are solved-for simultaneously as parts of the whole ice sheet application of the SSA stress balance. This whole ice sheet SSA computation is done at every time step of the dynamic equilibrium model. In many models the onset of sliding frequently arises from a transition from cold ice to ice at pressure-melting-temperature at the base, but in PISM-PIK no sliding onset is imposed there or elsewhere. Rather, the basal material yield stress $\tau_{\mathrm{c}}$ evolves according to the MohrCoulomb equation, Eq. (9), the driving stress evolves according to the mass continuity equation (Eq. 1 in Part 1), and the solution of the SSA itself determines whether the (regularized) plastic basal material fails and sliding occurs. Since the basal yield stress is a continuous function of ice thickness and topography in our parameterization (Eqs. 9-12) we ensure a smooth onset of sliding without prescribing any internal boundary conditions. The other transition, from grounded to floating ice, works also without imposing any boundary condition. The grounded/floating-mask is determined in every time step from the flotation criterion:

$b(x, y)=-\frac{\rho_{\mathrm{i}}}{\rho_{\mathrm{o}}} H(x, y)$.

Hence migration of the grounding line is - via the evolution of the ice thickness - determined by the velocities computed from the stress balance. Since, like in other SSA-models used for floating and grounded ice, velocities are computed non-locally and simultaneously for the shelf and as a sliding velocity for the sheet, they provide a natural way to take into account buttressing effects, and stress transmission across the grounding line is guaranteed. We believe that this provides a good alternative to boundary conditions being imposed at the grounding line in order to combine shelf flow and deformational flow inland in a large scale model.

Basal friction within the SSA equations, which is crucial for the magnitude of the computed sliding velocities, is calculated based on a model for plastic till (Schoof, 2006a)

$\tau_{\mathrm{b}_{i}}=-\tau_{\mathrm{c}} \frac{v_{i}}{\left(v_{x}^{2}+v_{y}^{2}\right)^{1 / 2}}$,

as described in Winkelmann et al. (2011). The basal yield stress $\tau_{\mathrm{c}}$ is given by the Mohr-Coulomb model for saturated till with zero cohesion (Paterson, 1994)

$\tau_{\mathrm{c}}=\tan \phi\left(\rho_{\mathrm{i}} g H-p_{\mathrm{w}}\right)$.

Strictly speaking, Eq. (8) only describes the basal stress in a perfectly-plastic basal model. This value of the yield stress 


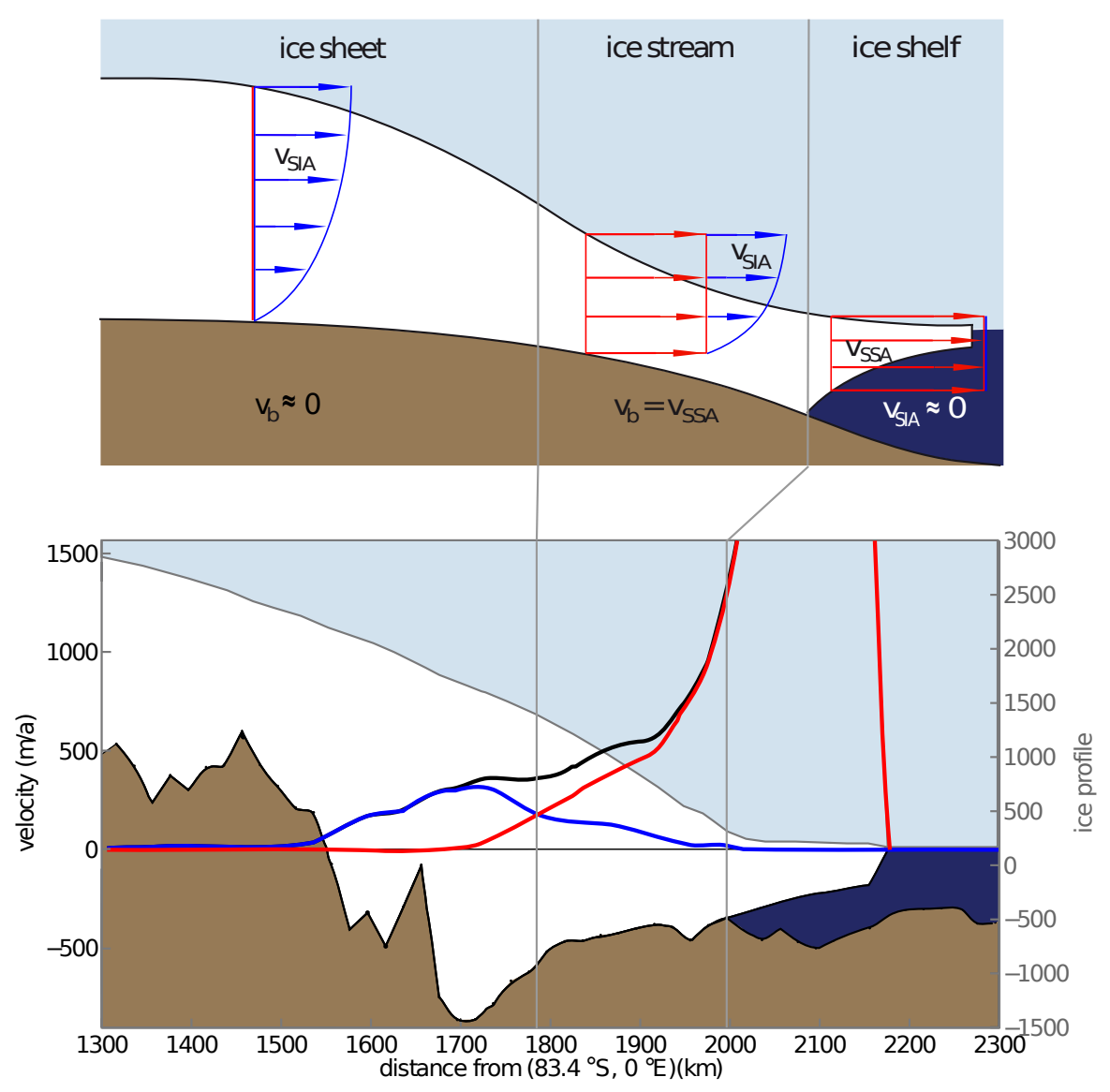

Fig. 2. Superposition of SIA and SSA velocities. Upper panel: a schematic diagram of an ice profile showing the different flow regimes in PISM-PIK. Repeats Fig. 1 from Winkelmann et al. (2011). Lower panel: an example cut through the sheet-stream-shelf transition of the Lambert Glacier and Amery Ice Shelf in the simulation. The location is shown by the green line in Fig. 8. The onset of an ice stream is defined diagnostically to be where the basal sliding velocity $\boldsymbol{v}_{\mathrm{b}}$ (red curve) exceeds the SIA velocity $\boldsymbol{v}_{\text {SIA }}$ (blue curve). The model output velocity $\boldsymbol{v}=\boldsymbol{v}_{\mathrm{b}}+\boldsymbol{v}_{\text {SIA }}$ is shown in black.

is only valid where sliding is occurring. Because the basal stress is computed by a regularized plastic law (Bueler and Brown, 2009, Eq. 27), however, at stresses lower than the yield stress there is a very small amount of sliding on the order of $10 \mathrm{~cm} \mathrm{a}^{-1}$ or less. Comparison to an exact solution of the perfectly-plastic model shows that this regularization indeed has only a small effect (Bueler and Brown, 2009). The designation of "non-sliding-ice" is therefore applied to the vast regions in the interior of the ice sheet with such negligibly small SSA velocities, recognizing that they would have exactly zero basal sliding in a perfectly-plastic model. For our simulation of Antarctica, the friction angle $\phi$ (Clarke, 2005 ) is parameterized with bed elevation as

$\phi(x, y)= \begin{cases}5^{\circ}, & b(x, y) \leq-1000, \\ 5^{\circ}+15^{\circ}\left(1+\frac{b(x, y)}{1000}\right), & -1000<b(x, y)<0, \\ 20^{\circ}, & 0 \leq b(x, y)\end{cases}$

The pore water pressure

$p_{\mathrm{w}}=0.96 \rho_{\mathrm{i}} g H \lambda$ is limited to a maximum of $96 \%$ of the overburden pressure $\rho_{\mathrm{i}} g H$ for maximal $\lambda$, i.e., for ice resting on bedrock at or below sea level. The scaling parameter $\lambda$, given by

$\lambda(x, y)= \begin{cases}1, & b(x, y)-z_{\mathrm{sl}} \leq 0, \\ \left(1-\frac{b(x, y)-z_{\mathrm{sl}}}{1000}\right) & 0<b(x, y)-z_{\mathrm{sl}}<1000, \\ 0, & 1000 \leq b(x, y)-z_{\mathrm{sl}},\end{cases}$

ranges, depending on sea level $z_{\mathrm{sl}}$ and bed elevation, from 0 to 1 . It can be interpreted as water content in the till. Bueler et al. (2010) and Bueler and Brown (2009), using base PISM, compute this water content thermodynamically from the basal melt rate. For simplicity and in order to focus here on the ice dynamics we choose to use a basal friction parameterization for the presented simulation according to Eqs. (812 ), which is only dependent on topography and ice thickness, decoupled from thermodynamics. It results in a pressure distribution which is similar to the thermodynamicallycomputed result (Fig. 4). This is especially the case in the crucial marine areas of the WAIS, where the PISM-PIK 
parameterization, exactly like the thermodynamical model, essentially gives uniformly full water content $(\lambda=1)$, leading to low basal resistance there allowing for slip or fast sliding. Thus effective pressure varies linearly between $4 \%$ of overburden pressure in marine areas and full overburden where the bed exceeds $1000 \mathrm{~m}$ a.s.l. The parameterization ensures a continuous transition to a quasi-non-slip regime in regions higher up, where the basal resistance is higher and sliding gets less and less pronounced, until it is negligibly small in the interior of the ice sheet, which can be regarded as frozen to the bedrock (see Figs. 3 and 2). The low basal resistance in marine areas is crucial for the development of fast flow and stream-like flow patterns as illustrated, for example, in Fig. 11. More data or also a new thermodynamical model providing a more detailed picture about the conditions at the base of the ice would be needed to precisely model the locations and velocities of streams in Antarctica. Inverse modeling (e.g., Macayeal, 1992; MacAyeal, 1993; Maxwell et al., 2008; Raymond and Gudmundsson, 2009; Joughin et al., 2009; Arthern and Gudmundsson, 2010; Goldberg and Sergienko, 2011) would improve the parameterization of basal friction, but basal friction is not the only control mechanism for the structure of what we identify as streams in this simulation. This is because they arise from the simultaneous solution of the thermomechanically-coupled SSA and SIA equations. The role of longitudinal stresses is critically important in generating convergence to credible continuum results, see Bueler and Brown (2009). Also the horizontal resolution is crucial in resolving ice streams, as the dimension of actual ice streams often is at or below the $\approx 20 \mathrm{~km}$ resolution used in this simulation.

When aiming at modeling different flow regimes, the isotropic (Glen) flow law used here (Winkelmann et al., 2011, Eqs. 4-5) might not be the best choice. Ma et al. (2010) suggest that velocities in the grounded part of an ice sheet are often underestimated by models using such isotropic laws, while they are overestimated in ice shelves. In applying PISM-PIK to the Antarctic sheet-shelf system we adjust for un-modeled anisotropy, and also for other uncertainties relating to unobserved variations in viscosity and basal resistance, by using different enhancement factors for the SIA $\left(E_{\mathrm{SIA}}\right)$ and the SSA $\left(E_{\mathrm{SSA}}\right)$. Note $E_{\mathrm{SIA}}>1$ and $E_{\mathrm{SSA}}<1$; see Table A1 for values. This difference in quality for the two enhancement factors is justified by the fact that under compression the fabric of ice becomes axisymmetric and easier to shear than isotropic ice, whereas under tension girdletype fabrics evolve and make the ice stiffer (Ma et al., 2010). In PISM-PIK we use a uniform enhancement factor for the SSA, but, because the SSA velocity is interpreted as the sliding velocity for grounded ice, the effective flow enhancement arising from the superposition decreases for ice flowing through the transition from sheet to shelf; compare Fig. 2.

At all types of ice margins the SSA stress balance is subject to a physically motivated stress boundary condition (for details see Sect. 2.4 in Winkelmann et al., 2011). For ice
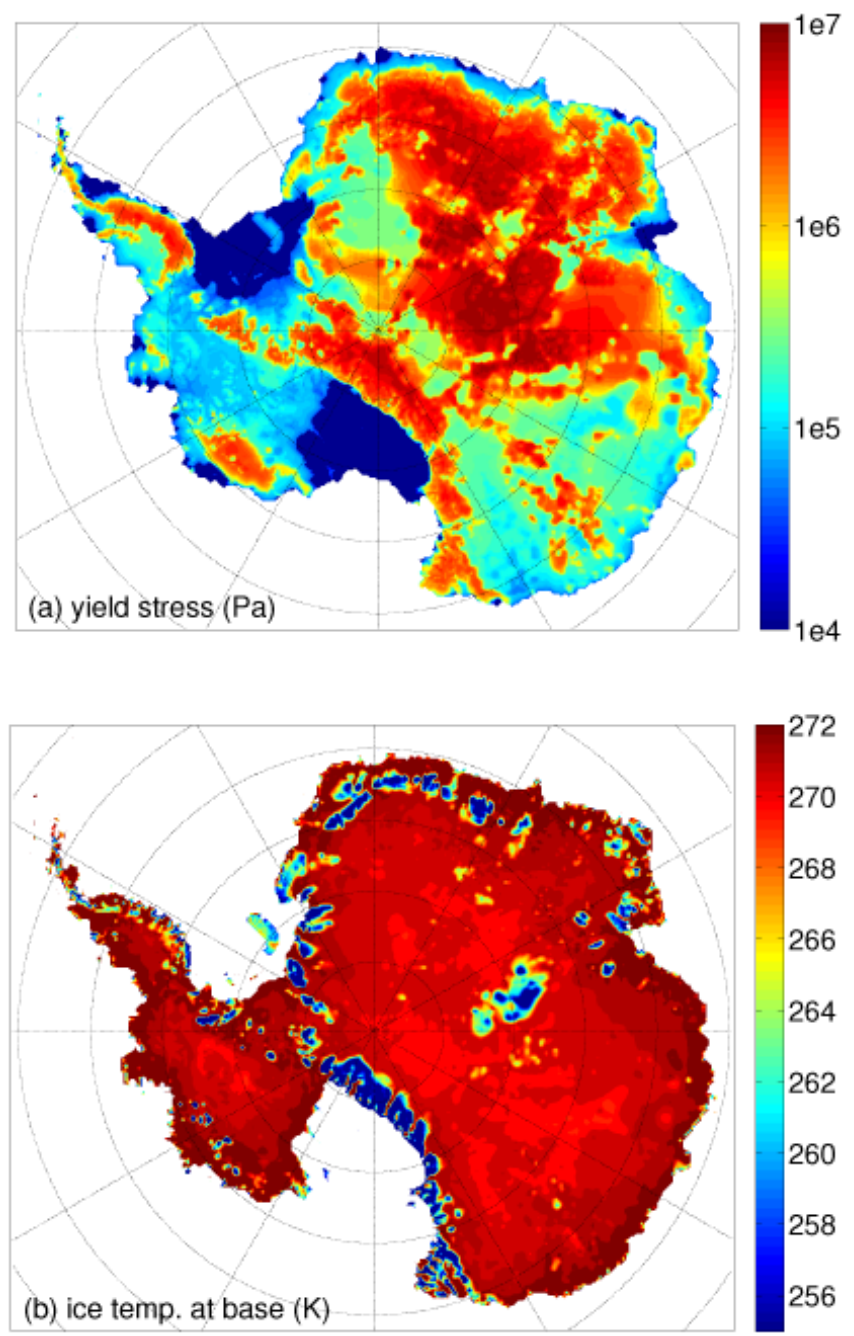

Fig. 3. (a) Map of yield stress $\tau_{\mathrm{c}}$, following Eqs. (9-12). (b) Temperature at the base of grounded ice.

shelves, a subgrid-interpolation of the calving front enables continuous advance and retreat and also ensures a steep front, which is necessary for a proper evaluation of the stresses there (see Albrecht et al., 2011). Advance of the calving front naturally happens through mass transport governed by the continuity scheme, while retreat is governed by a new physically-motivated calving law.

In fact, following Levermann et al. (2011), calving occurs in regions of divergent flow where both eigenvalues $\dot{\epsilon}_{ \pm}$of the horizontal strain rate tensor are positive. In such cases we define the calving rate to be

$C=K \operatorname{det}(\dot{\boldsymbol{\epsilon}})=K \dot{\epsilon}_{+} \dot{\epsilon}_{-} \quad$ for $\quad \dot{\epsilon}_{ \pm}>0$

with $K>0$ being a proportionality constant. This calving law allows for realistic calving fronts for various types of shelves, e.g., relatively thin ones like Larsen $\mathrm{C}$ with ice thicknesses $H_{\mathrm{c}}$ of about $170-220 \mathrm{~m}$ at the calving front as well as for Ross $\left(H_{\mathrm{c}} \approx 220-395 \mathrm{~m}\right)$ and Ronne $\left(H_{\mathrm{c}} \approx 320-340 \mathrm{~m}\right)$. The 

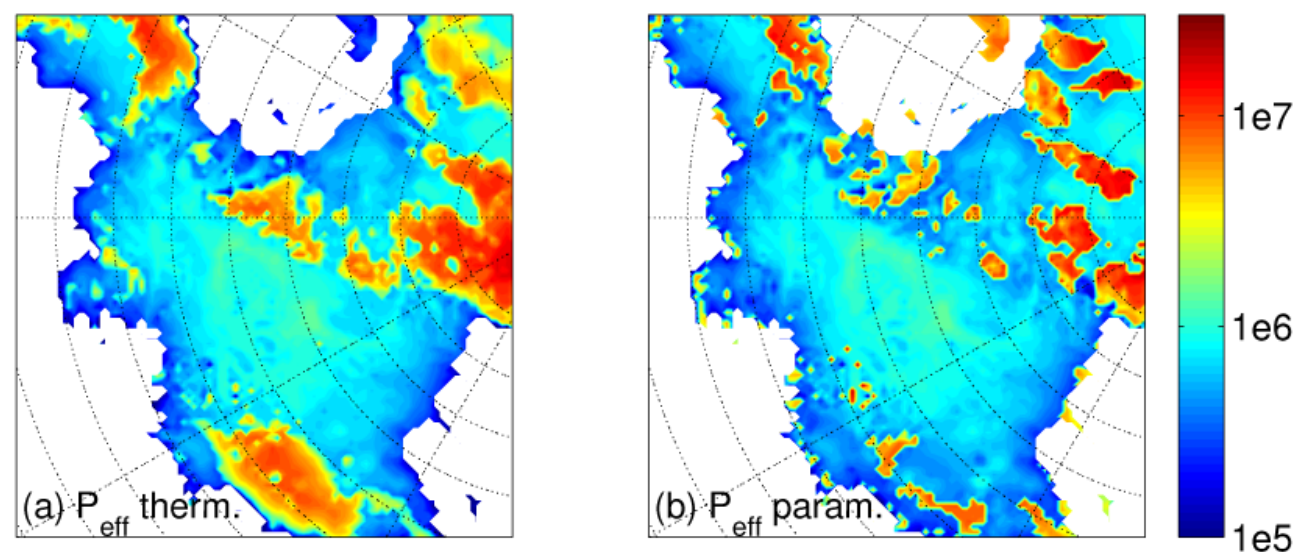

Fig. 4. Effective pressure with pore water pressure according to Eq. (11) with (a) $\lambda$ thermodynamically computed as in Bueler and Brown (2009) and (b) parameterized according to Eq. (12).

new calving law ensures that shelf ice is cut off at the mouth of bays, like the Ross bay, for example. In Fig. 5 the alongflow eigenvalue $\dot{\epsilon}_{+}$for our simulations is illustrated together with the zero lines for the across-flow eigenvalue $\dot{\epsilon}_{-}$. In most parts, this second eigenvalue is negative, indicating compression within the shelf. Regions where $\dot{\epsilon}_{-}$is positive - indicating expansion in the transversal direction - are critical in the sense that once a calving front retreats back to such a position a new stable calving front position is established. Convergence of ice flow can be produced by pinning points like ice rises, islands or predominant coast features, which stabilize the calving front.

\section{Performance in equilibrium simulation}

PISM-PIK as described above in Sect. 2 was applied to the Antarctic ice-sheet-shelf system in a dynamic equilibrium simulation using time-invariant input data. After initialization with presently-observed fields the model reached an equilibrium with $258 \times 10^{14} \mathrm{~m}^{3}$ ice volume compared to the $256 \times 10^{14} \mathrm{~m}^{3}$ deduced from the ALBMAP data set. The first part of the spin up procedure consisted of a $200000 \mathrm{yr}$ model run with fixed geometry and non-evolving surface such that the three-dimensional temperature field within the ice body could evolve to equilibrium according to the conservation of energy equation. Afterwards the dynamic equilibrium simulation using the physical framework described in Winkelmann et al. (2011) ran for $150000 \mathrm{yr}$ using the boundary conditions described in Sect. 2 and the parameter values from Table A1. After this the model is in thermal equilibrium as well as in geometric quasi-equilibrium in the sense that its drift in sea-level relevant ice volume is less than $-0.000025 \%$ in $1000 \mathrm{yr}$, which is equivalent to an average sea-level rise of $\approx 0.0014 \mathrm{~mm} \mathrm{yr}^{-1}$. (To compute the sea-level-relevant ice volume the total grounded volume was reduced by the amount of ice, that - in liquid form - would fill up the re-
Table 1. Comparison with observations of key quantities in the PISM-PIK dynamical equilibrium simulation (Lythe et al., 2001; Le Brocq et al., 2010). The column labeled "difference" is the amount by which the model result exceeds observations.

\begin{tabular}{llll}
\hline Quantity & Observations & PISM-PIK & Difference \\
\hline Total ice volume & $256 \times 10^{14} \mathrm{~m}^{3}$ & $258 \times 10^{14} \mathrm{~m}^{3}$ & $+0.8 \%$ \\
Grounded ice volume & $249 \times 10^{14} \mathrm{~m}^{3}$ & $254 \times 10^{14} \mathrm{~m}^{3}$ & $+2.0 \%$ \\
Total ice area & $137 \times 10^{11} \mathrm{~m}^{2}$ & $136 \times 10^{11} \mathrm{~m}^{2}$ & $-0.7 \%$ \\
Grounded ice area & $123 \times 10^{11} \mathrm{~m}^{2}$ & $125 \times 10^{11} \mathrm{~m}^{2}$ & $+1.6 \%$ \\
Floating ice area & $143 \times 10^{10} \mathrm{~m}^{2}$ & $111 \times 10^{10} \mathrm{~m}^{2}$ & $-22.4 \%$ \\
Ice front type: marine & $28 \%$ & $54 \%$ & - \\
Ice front type: cliff & $25 \%$ & $23 \%$ & - \\
Ice front type: shelf & $47 \%$ & $23 \%$ & -
\end{tabular}

gions with bedrock below sea level, if all ice were removed.) The total ice volume is subject to larger fluctuations due to calving events which occur on a timescale of decades and are of the same magnitude as this drift shows in $20000 \mathrm{yr}$.

Table 1 provides key features and characteristic quantities of Antarctica, comparing the equilibrium state produced in PISM-PIK with observations from the ALBMAP dataset. Note, however, that the observed Antarctic Ice Sheet cannot be assumed to be in steady state, and hence the comparison performed here has to be regarded considering that fact. An alternative spin up procedure simulating a glacial-interglacial shift has the disadvantage that the best-quality constraints on prior climate, like temperatures and accumulation rates extracted from ice cores, can still only generate a very rough approximation of the boundary inputs to the ice flow model, for example the time-dependent surface temperature and accumulation maps. The steady state reached in the presented equilibrium simulation will be further analyzed by considering the geometric configuration (in Sect. 3.1), the mass budget (in Sect. 3.2) and the steady-state dynamics (in Sect. 3.3). 

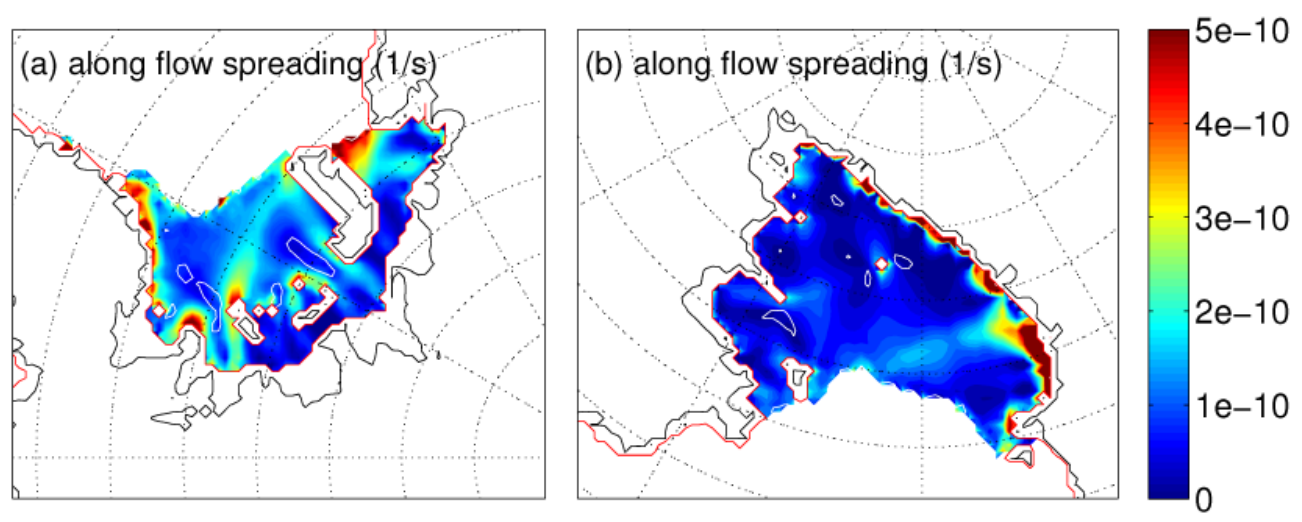

Fig. 5. Calving law applied to (a) Ronne-Filchner and (b) Ross Ice Shelves. Blue shading represents the spreading rate $\dot{\epsilon}_{+}$along the main flow direction, white lines (zero line of $\dot{\epsilon}_{-}$) illustrate possibly weak shelf regions where transversal spreading occurs. (Grounding line is represented by red line, onset of streams by black lines.)

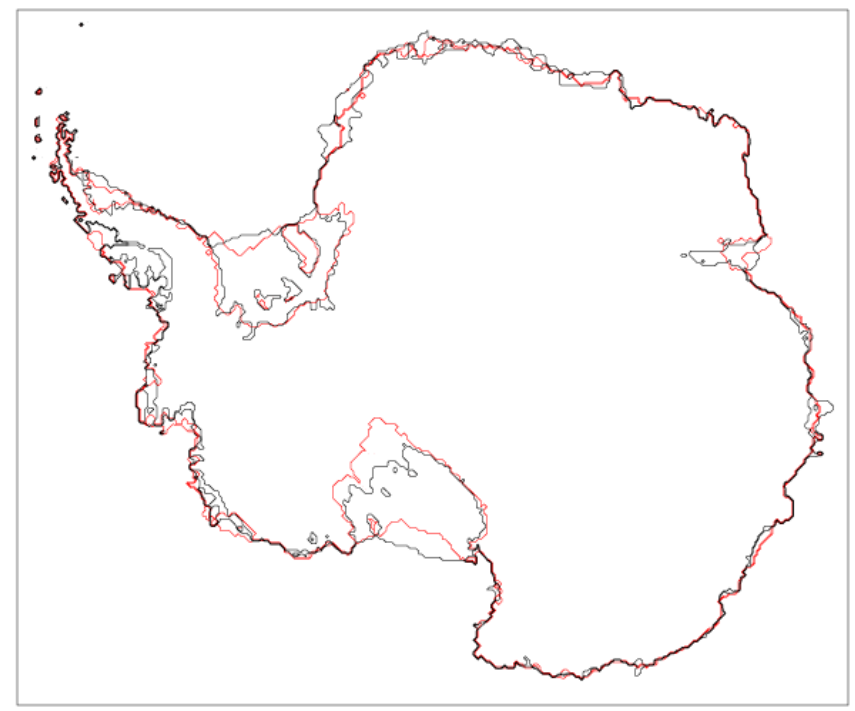

Fig. 6. Comparison of grounding-line and ice-front positions from ALBMAP dataset (black) and PISM-PIK dynamic equilibrium simulation (red).

\subsection{Geometric configuration in steady state}

In PISM-PIK all lateral boundaries are free to evolve: the grounding line, as well as (floating) calving fronts and grounded ice fronts (marine margins) are shown in Fig. 8. Another type of grounded ice fronts are cliffs. Those are ice resting on bedrock above sea surface, adjacent to the ocean, which in a lateral-view finite-differences visualization resemble an ice-covered cliff at the coast. Would the ice margin move past such a location towards the ocean, where the bed then lies below sea-level, a marine margin or a shelf front would develop. In Fig. 6 we present a comparison between observation (Lythe et al., 2001; Le Brocq et al., 2010) and simulation of the position of those lateral boundaries.
The Ross Ice Shelf front as well as the front of the RonneFilchner Ice Shelf are well-captured by the applied calving law (Levermann et al., 2011). The position of the front of Larsen C Shelf, which is clearly thinner than the other two shelves is also reproduced by the same calving law. This result cannot be obtained by a simple ice-thickness calving law where floating ice thinner than a certain global threshold value is rigorously cut off. However, our model resolution of $\approx 20 \mathrm{~km}$ fails to capture a number of the smaller ice shelves that consist of a handful or fewer grid cells. This is also reflected in the partitioning of ice-front types, which differs from the observational data as shown in Table 1.

The simulated grounding line of the Ross Ice Shelf lies further inland than observed. Preparatory experiments have shown that its position is strongly dependent on topography (via the parameterization of basal resistance, Eqs. 8-12), on the melt rate at the base of the adjacent ice shelf, and on the velocities in the shelf, which in turn are subject to the enhancement factor $E_{\mathrm{SSA}}$. For the reasons presented in Sect. 2 we believe that with the SIA/SSA hybrid presented here we employ a very reasonable scheme for grounding line dynamics including buttressing effects. Yet, since we start our equilibrium simulation with the configuration of the present day Antarctic ice sheet, the variability of the grounding line under climate forcing has to be shown additionally. In a simple setup this has been done by Winkelmann et al. (2011), where in experiments from the MISMIP inter-comparison (Schoof et al., 2009) the reversibility of the grounding line migration on a sloping bed has been demonstrated. This has been achieved without the application of any boundary condition at the grounding line, its position being determined solely by the flotation criterion. For the Antarctica setup we applied a non-representative sinusoidal surface temperature forcing with an amplitude of $7.5 \mathrm{~K}$ and period of $100000 \mathrm{yr}$ to the equilibrium state presented here. This results in grounding line migration back and forth as shown in the animation in the Supplement. 

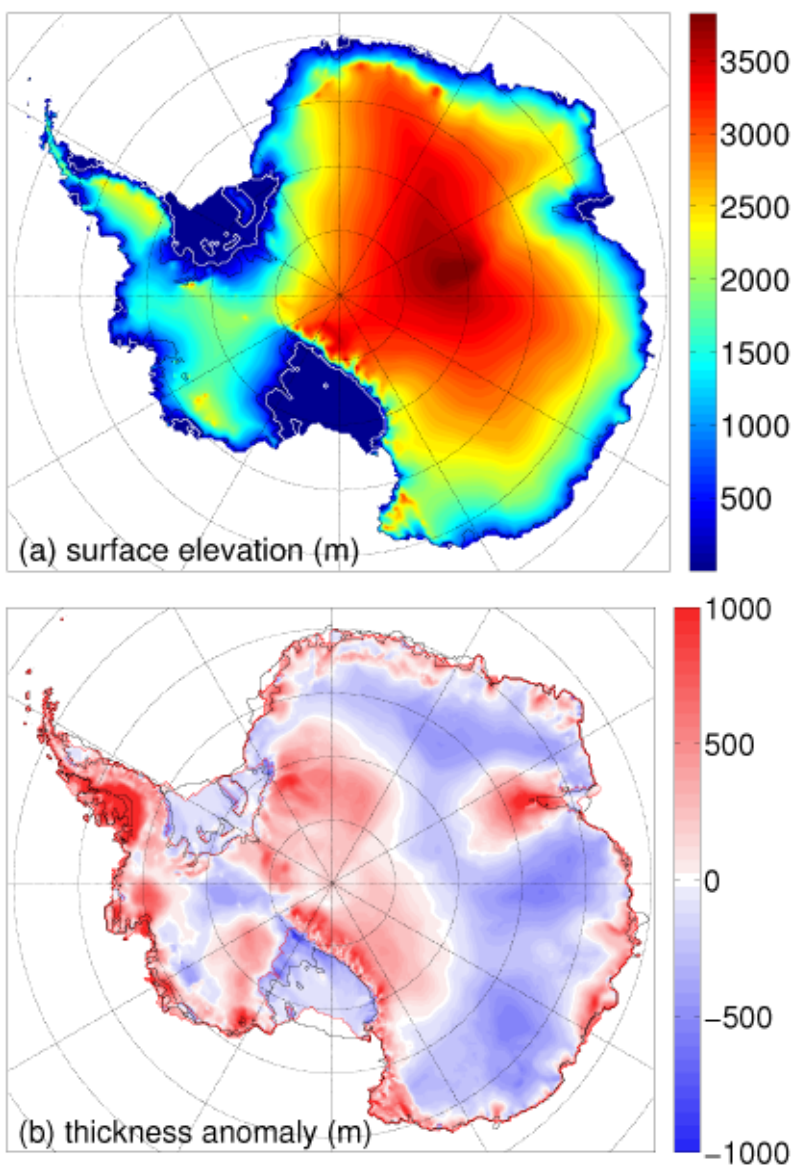

Fig. 7. (a) Surface elevation in model equilibrium. (b) Difference in ice thickness: dynamic equilibrium simulation minus ALBMAP data. Red indicates model overestimation of ice thickness while blue is underestimation.

In Fig. 7 modeled surface elevation is given as well as a comparison of ice thickness to observation. The majority of the grid cells show a deviation in ice thickness of not more than a couple of hundred meters (positive or negative, Fig. 7b). The combination of the positive anomalies in the Amery region and directly upstream of the grounding line of the Ross Ice Shelf, the Pine Island Glacier and the Filchner Ice Shelf, and the negative anomaly for the West Antarctic Ice Sheet and large parts of the East Antarctic Ice Sheet explains the total difference of only $0.8 \%$ of the total ice volume, $258 \times 10^{14} \mathrm{~m}^{3}$ in the simulation as compared to $256 \times 10^{14} \mathrm{~m}^{3}$ observed, see Table 1 . One of the stronger positive deviations in ice thickness occurs in the Amery Shelf area. While the model reproduces the general structure of this region, the outflow here is apparently underestimated, although a strong improvement was achieved by use of the ALBMAP data set by Le Brocq et al. (2010) relative to earlier use of BEDMAP (Lythe et al., 2001) in the model. With few exceptions the ice thickness in the simulation is underestimated along the modeled ice divides, while it is overestimated in the regions of strong outflow (see Fig. 11).

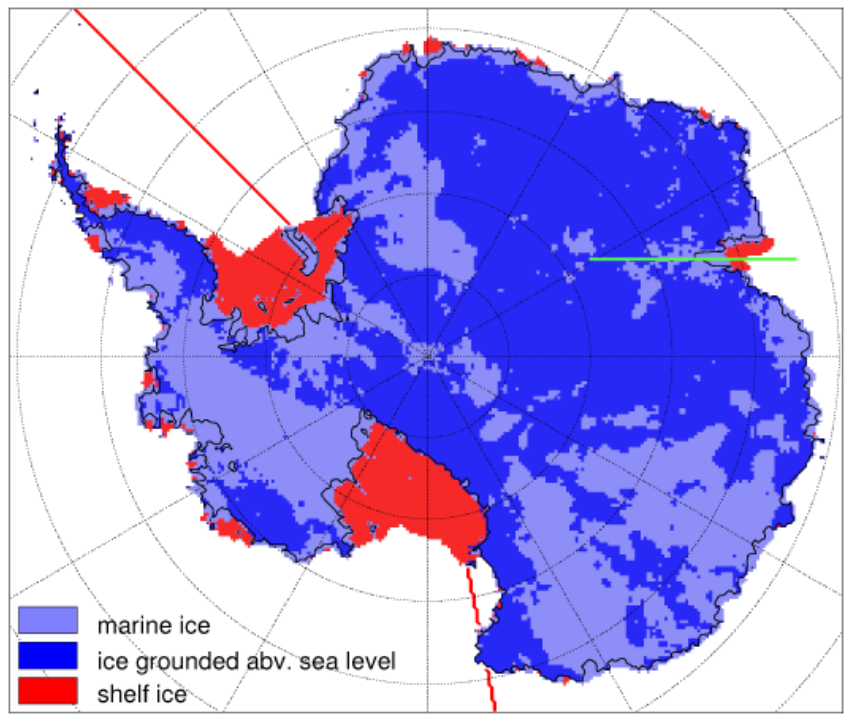

Fig. 8. Modeled distribution of different types of ice grid cells: shelves are red, ice grounded above sea level is blue and ice grounded below sea level (marine ice) is light blue. The onset of ice streams, defined diagnostically by inequality Eq. (6), is outlined in black. The green line indicates the cut through the sheet-shelf transition zone in the Amery region shown in profile in Fig. 2. The red lines along $45^{\circ} \mathrm{W}$ and $169^{\circ} \mathrm{E}$ longitude, respectively, indicate the partitioning of the ice sheet into West Antarctica and East Antarctica.

\subsection{Mass balance}

The geometric configuration as described above is determined by the ice fluxes in steady state which are allocated to shelf ice, marine ice and ice grounded above sea-level. The partitioning of the different types of ice cells in the equilibrium simulation is depicted in Fig. 8. In steady state the surface mass balance, which is held constant in the simulation, is balanced by the bottom mass balance (subsheet and subshelf melting and refreezing) and the flux across the ice front. In terms of total mass flux, the bottom mass balance plays a negligible role, while the crucial contribution is the flux across the ice front. The ice front is composed of marine ice cells, cliffs and floating front cells as shown in Fig. 9a. For all types of ice fronts - for each the stress boundary condition is applied accordingly (see Eqs. 26-28 Winkelmann et al., 2011, for details) - mass loss occurs through calving. In the case of cliffs and marine fronts the subgrid treatment of the front has not yet been implemented, the calving happens through the formation of shelves which are only one grid-box long, and then calve off in the same time step. This means that the stress evaluation at the grounded margin determines the amount of ice that is transported into the adjacent ocean cell. In an equilibrium situation this amount is so small that a very thin - typically only a few meters thick - ice shelf develops, which is subject to calving in the same time step, 
(a) type of ice front

(b) flow rate through ice front
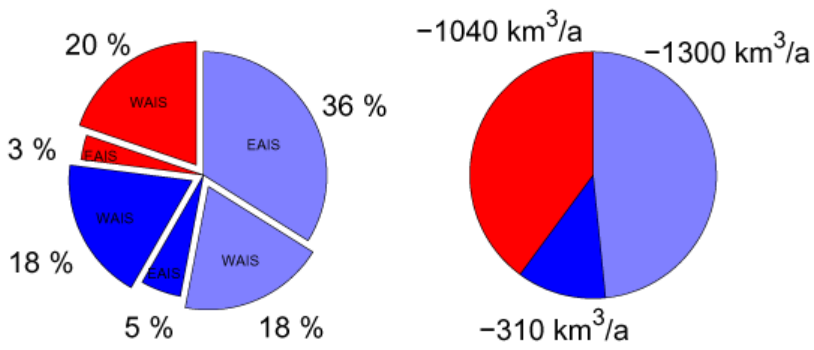

marine ice

cliff

shelf

Fig. 9. (a) Partitioning of the different types of ice fronts in the equilibrium simulation, and (b) their contribution to the mass budget. Note that an ice flow of $-1190 \mathrm{~km}^{3} \mathrm{a}^{-1}$ can be attributed to East Antarctica.

before the stresses are evaluated again at a grounded margin. Figure $9 \mathrm{~b}$ shows that most of the mass loss occurs at marine ice fronts and shelves. Only a small part occurs at cliffs (about $12 \%$ ) relative to their extent ( $23 \%$ of the ice front of Antarctica is comprised of cliffs). Conversely, although shelves account for only $23 \%$ of the total modeled ice front of Antarctica, they provide $39 \%$ of the mass loss. This can be explained by the different magnitude of velocities in sheet and shelves which will be further discussed in Sect. 3.3. Also, in regions with high outflux the model tends to produce ice shelves. The formation of shelves influences the grounded ice upstream and thereby the mass balance both by buttressing effects in the case of an embayment and through the drawdown of grounded ice. As shown in Sect. 3.1 the total ice shelf area in our simulation is smaller than in observation. A subgrid treatment of grounded margins analogous to that for the calving fronts, and higher resolution, might improve this.

\subsection{Steady state dynamics}

The ice geometry, grounding line position, ice front position, and ice front type each evolve to an equilibrium at the end of the simulation. In Fig. 10 the surface velocities for this steady state are detailed for the West Antarctic Ice Sheet. In Fig. 11 the flow pattern for the whole Antarctic ice sheet is shown, with the onset of streams as defined by equation 6 marked by black lines. As described in Sect. 2 streams are (diagnostically) distinguished from the surrounding ice by comparing the sliding velocity $\boldsymbol{v}_{\mathrm{b}}=\boldsymbol{v}_{\mathrm{SSA}}$ to the vertically averaged velocity $\overline{\boldsymbol{v}}$ : if $\boldsymbol{v}_{\mathrm{b}}>\overline{\boldsymbol{v}}-\boldsymbol{v}_{\mathrm{b}}$ then we consider the flow stream-like. The overall pattern of drainage basins is easily recognizable: for WAIS there is drainage into the Amundsen Sea sector, an area subject to accelerated thinning in reality (Thomas et al., 2004; Pritchard et al., 2009). A feature that can be roughly identified with Thwaites Glacier plays a more

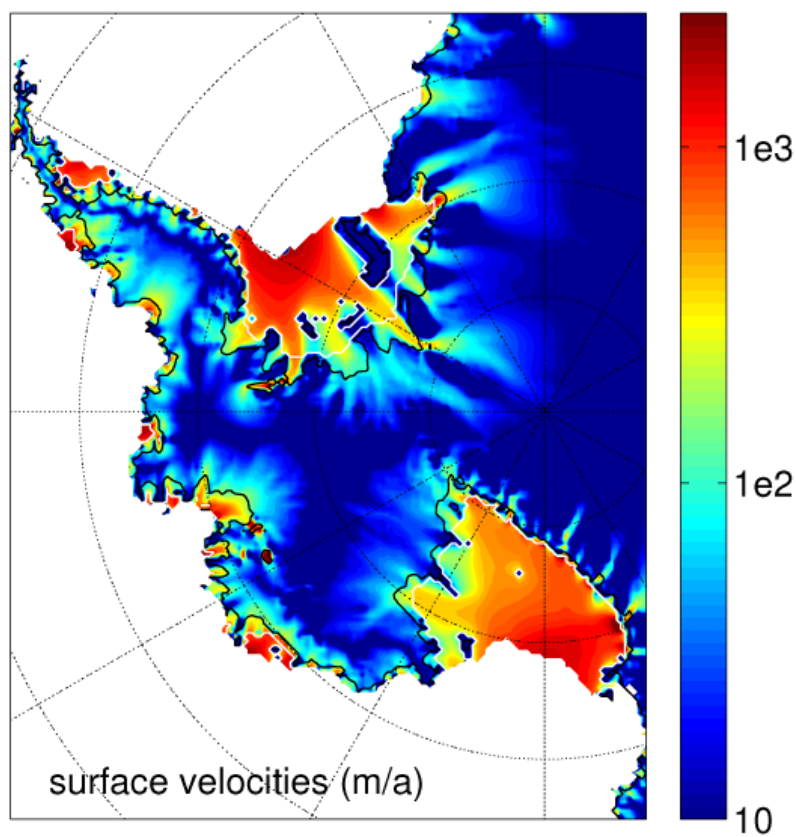

Fig. 10. Modeled surface velocity for the West Antarctic Ice Sheet. White lines show the grounding-line position, thin black lines indicate ice streams according to inequality Eq. (6).

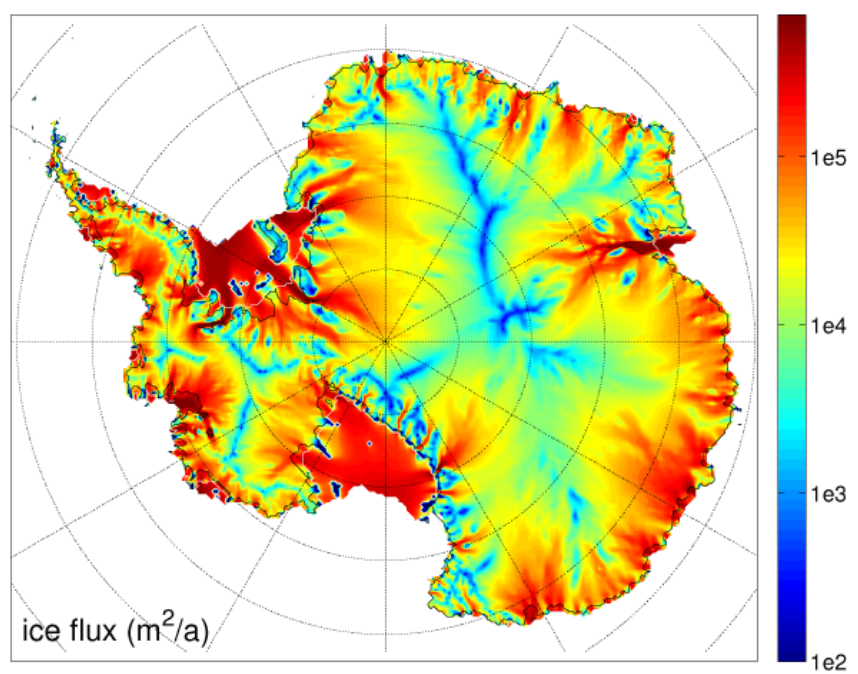

Fig. 11. Modeled vertically-integrated horizontal ice flux. Ice streams are outlined in black, grounding line position in white.

prominent role in the flow field of our simulation than Pine Island Glacier. The latter has its grounding line further seaward than in reality. These differences might be due to the $\approx 20 \mathrm{~km}$ resolution in our model. Drainage into the Ronne Shelf occurs from several different basins, both north and south of the Ellsworth mountains. Another prominent feature is the drainage from East Antarctica into the Ross Ice Shelf via the Byrd and Mulock Glaciers. In East Antarctica the main drainage basins can be connected to the marine areas as 

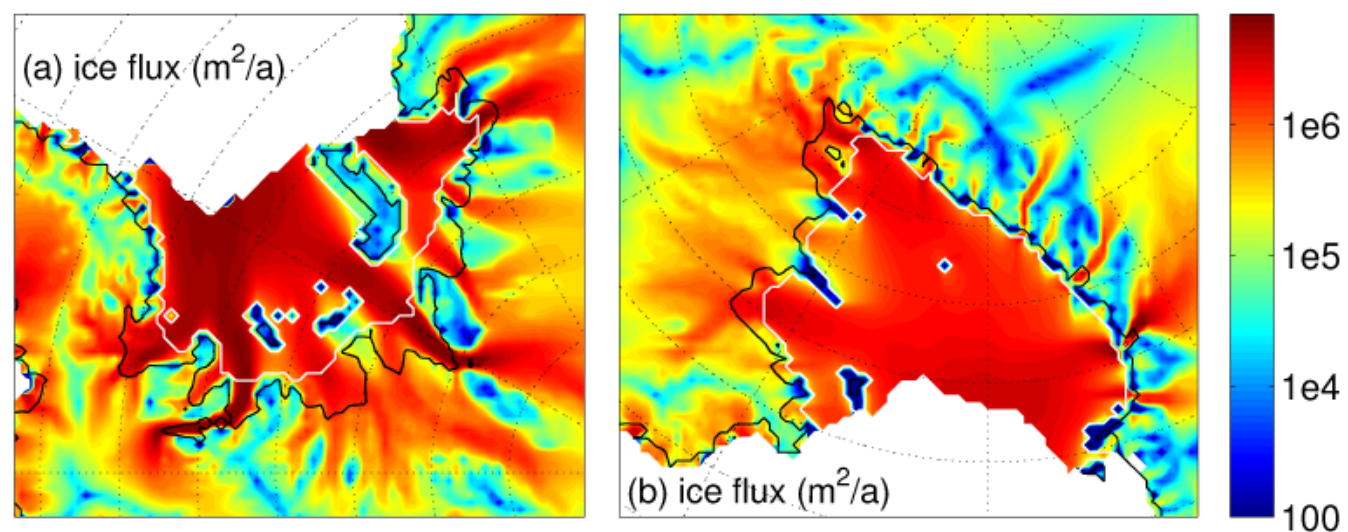

Fig. 12. Ice flux with streams indicated by black line for (a) Ronne-Filchner and (b) Ross Ice Shelves. The grounding line is marked by a white line.
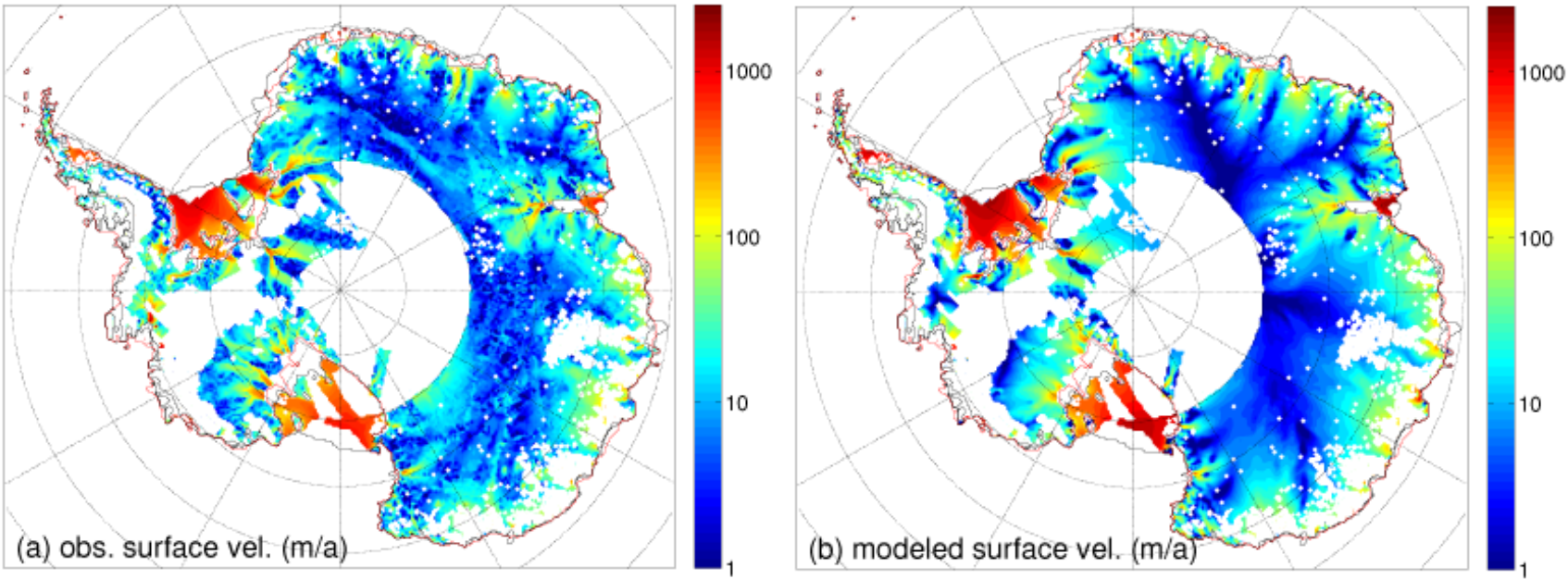

Fig. 13. Comparison of surface velocity fields. (a) Observed surface velocities from MAMM data enriched by data from Joughin et al. (2002). (b) Surface velocities from equilibrium simulation. In both (a) and (b), regions without observational coverage and where there is no agreement in the simulation and the observations about whether the ice is grounded or floating are masked out, which leaves $65 \%$ of total ice covered area for comparison. The respective grounding line positions and calving fronts for observation and model are depicted in black and red, as in Fig. 5.

shown in Fig. 8, indicating the strong influence of bottom topography on our simulation. Figure 12 shows the ice flux for the combined stream-shelf system for the two largest shelves. Due to the anomaly in the position of the grounding line the location of the stream-like features in the simulation cannot directly coincide with real streams in Antarctica. Combining the SIA and SSA velocities as described in Sect. 2 is, however, shown to model stream-like features in a reasonable way.

In order to compare these model results to observational data we combined two sources, namely present-day surface velocities from both the Modified Antarctic Mapping Mission (Jezek et al., 2003; Liu et al., 1999) and for the Siple Coast area of WAIS, from Joughin et al. (2002), see Fig. 13a. Regions where there is no agreement in the simulation and the observations about whether the ice is grounded or floating are masked out, so that details in some of the most interesting regions near ice margins are lacking. A comparison to balance velocities in those regions is no alternative, because they are a model for ice flow based on observations of surface elevation and precipitation, but unconstrained by conservation of energy or conservation of momentum. Also, they substantially differ from observations themselves (see, e.g., for the Siple Coast Area Fig. 1 in Bamber et al., 2000). The observed surface velocities are compared to the modeled surface velocities in Fig. 13. The modeled magnitude deviates from observations in some areas, but the overall pattern and distribution of velocities in shelves, streams and areas frozen to the bed is clearly comparable. This is further supported by the scatter plot of velocity magnitudes (Fig. 14), illustrating the 


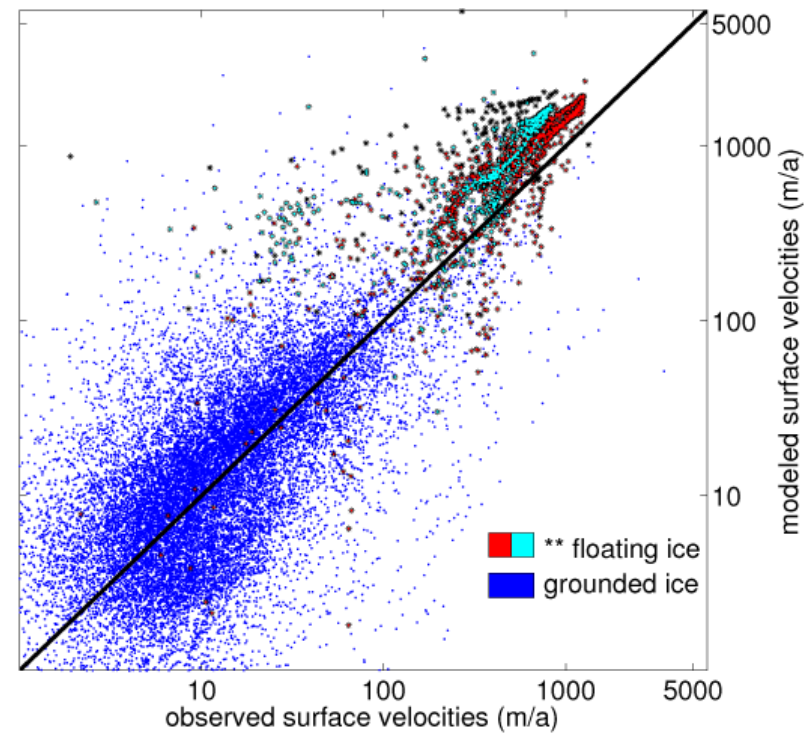

Fig. 14. Point-by-point scatterplot of modeled and observed velocities. The mean difference from modeled to observed velocities for grounded points is $\approx 4 \mathrm{~m} \mathrm{a}^{-1}$ with a standard deviation from this mean difference of $\approx 81 \mathrm{~m} \mathrm{a}^{-1}$. For floating points we get a larger difference of $\approx 334 \mathrm{~m} \mathrm{a}^{-1}$ with a standard deviation of $\approx 309 \mathrm{~m} \mathrm{a}^{-1}$. The stars with red points are the floating velocities that belong to the Ronne-Filchner Ice-Shelf, while the ones with the cyan points belong to the Ross Ice Shelf.
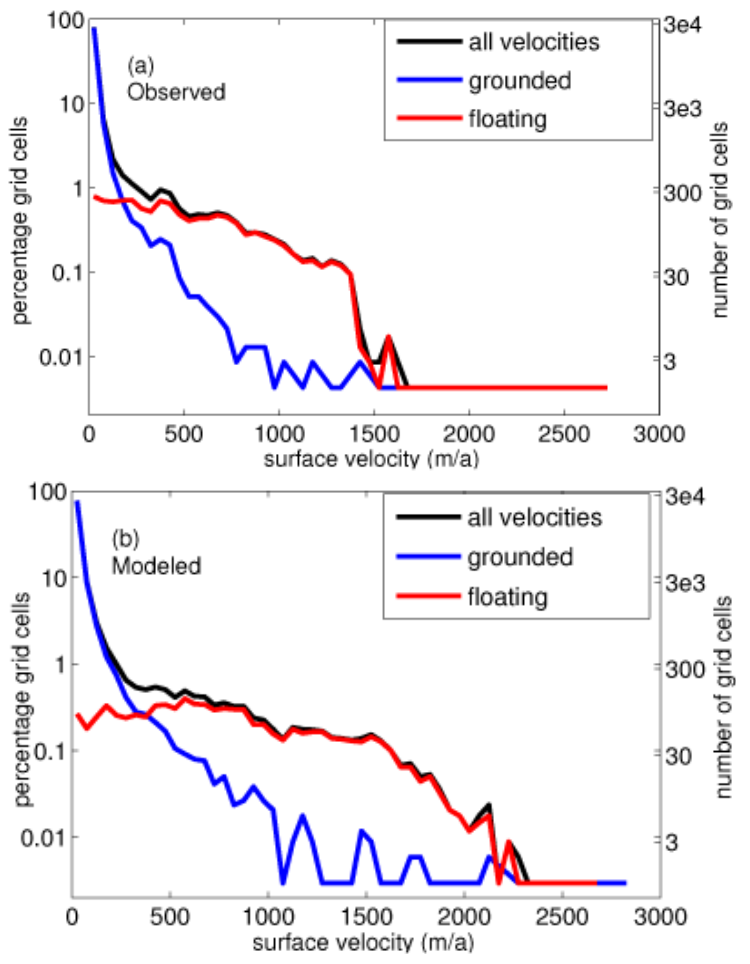

Fig. 15. Histogram of velocity distribution. (a) observed (b) modeled. Each of the 60 bins contains a velocity range of $\Delta v_{\text {surface }}=50 \mathrm{~m} \mathrm{a}^{-1}$.
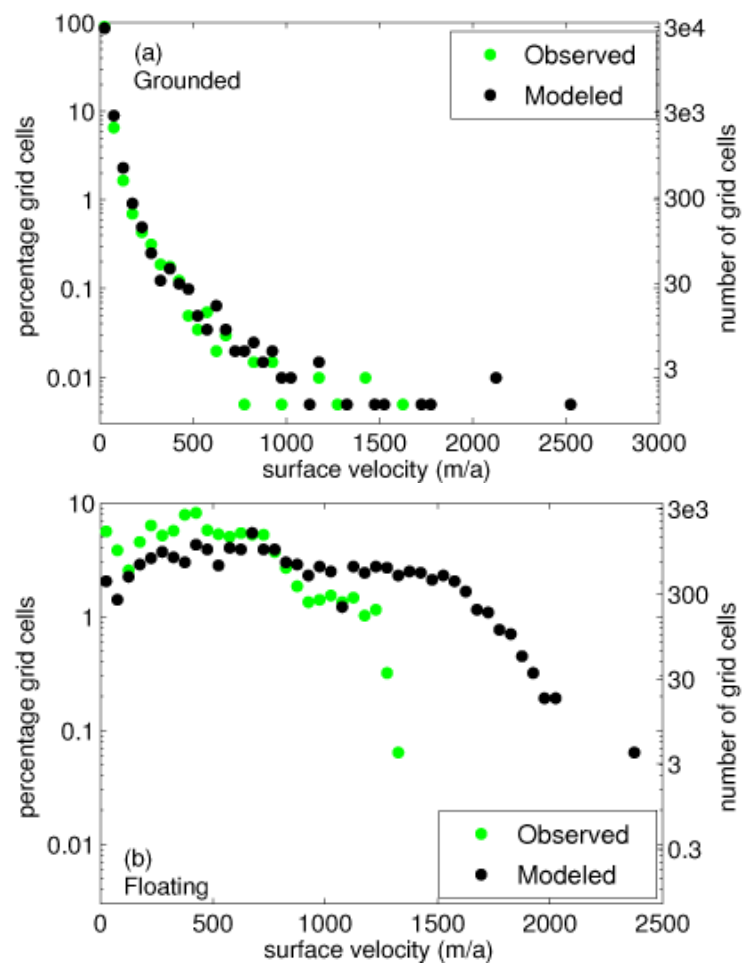

Fig. 16. Histogram of velocity distribution. Panel (a) grounded and panel (b) floating areas (please note that the strongest overestimation occurs only for a small number of grid cells). Relative to Fig. 15, we show results from the smaller dataset (Fig. 13), containing only data where there is agreement between model and observation about whether the ice is grounded or floating.

close correlation between the modeled and observed velocities. The comparison shows that while the grounded modeled velocities are in good agreement with observations, the velocities on the shelves are overestimated with a mean difference of $\approx 334 \mathrm{~m} \mathrm{a}^{-1}$ subject to a high variance (standard deviation $\approx 309 \mathrm{~m} \mathrm{a}^{-1}$ ). The differences vary from shelf to shelf. A histogram of the velocity distribution is given in Fig. 15. The Antarctic ice sheet has a large number of lowvelocity and a small number of high-velocity grid cells. For both simulation and observation we see that the number of grounded grid cells decreases with increasing velocity, while the number of floating grid cells is relatively constant in the low velocity range and then decreases. The histogram in Fig. 16 is based on the subset of observed velocity points shown in Fig. 13 matching the ice type in the simulation. A decomposition into grounded and floating regions reveals that high velocities are predominantly found on ice shelves. This also shows the limitations of PISM-PIK in reproducing the details of the observed velocity distribution: there are more floating cells in the quasi-uniformly distributed lowvelocity range in observations than our model can reproduce. On the other hand, cells with higher velocities on shelves 
Table A1. Table of symbols and values of constants.

\begin{tabular}{|c|c|c|c|}
\hline Symbol & Description & SI units & Value \\
\hline$b$ & bedrock elevation & $\mathrm{m}$ & \\
\hline$C$ & calving rate & $\mathrm{ms}^{-1}$ & \\
\hline$c_{p_{\mathrm{o}}}$ & $\begin{array}{l}\text { specific heat capacity of ocean } \\
\text { mixed layer }\end{array}$ & $\mathrm{J}(\mathrm{kg} \mathrm{K})^{-1}$ & 3974 \\
\hline$E_{\text {SIA }}$ & enhancement factor for the SIA & & 4.5 \\
\hline$E_{\text {SSA }}$ & enhancement factor for the SSA & & $0.8^{n}=0.512$ \\
\hline$F_{\text {melt }}$ & parameter for subshelf melting & $\mathrm{ms}^{-1}$ & $5 \times 10^{-3}$ \\
\hline$G$ & geothermal flux & $\mathrm{W} \mathrm{m}^{-2}$ & \\
\hline$g$ & acceleration due to gravity & $\mathrm{ms}^{-2}$ & 9.81 \\
\hline$h$ & upper surface elevation of ice & $\mathrm{m}$ & \\
\hline$H$ & ice thickness & $\mathrm{m}$ & \\
\hline$H_{\mathrm{c}}$ & ice thickness at calving front & $\mathrm{m}$ & \\
\hline$\{i, j\}$ & 2-D horizontal tensor indices & & \\
\hline$K$ & $\begin{array}{l}\text { proportionality constant for } \\
\text { Eigen Calving }\end{array}$ & $\mathrm{ms}$ & $10^{19}$ \\
\hline$L_{\mathrm{i}}$ & latent heat capacity of ice & $\mathrm{J} \mathrm{kg}^{-1}$ & $3.35 \times 10^{5}$ \\
\hline$n$ & Glen flow law exponent & & 3 \\
\hline$p_{\mathrm{W}}$ & pore water pressure & $\mathrm{Nm}^{-2}$ & \\
\hline$Q$ & horizontal ice flux & $\mathrm{m}^{2} \mathrm{~s}^{-1}$ & \\
\hline$\widetilde{S}$ & $\begin{array}{l}\text { ice equivalent basal mass } \\
\text { balance }(S>0 \text { is melting })\end{array}$ & $\mathrm{ms}^{-1}$ & \\
\hline$S_{\mathrm{O}}$ & $\begin{array}{l}\text { salinity of ocean water under ice } \\
\text { shelves }\end{array}$ & psu & 35 \\
\hline$T$ & ice temperature & $\mathrm{K}$ & \\
\hline$T_{\mathrm{f}}$ & freezing temperature & $\mathrm{K}$ & \\
\hline$T_{\mathrm{S}}$ & surface temperature & $\mathrm{K}$ & \\
\hline$T_{\mathrm{O}}$ & temperature of ocean water & $\mathrm{K}$ & $271.45\left(-1.7^{\circ} \mathrm{C}\right)$ \\
\hline$T_{\mathrm{pm}}$ & pressure-melting temperature & $\mathrm{K}$ & \\
\hline$v$ & overall horizontal ice velocity & $\mathrm{ms}^{-1}$ & \\
\hline$v_{\mathrm{b}}$ & $\begin{array}{l}\text { basal ice velocity; } \\
\boldsymbol{v}_{\mathrm{b}}=\boldsymbol{v}_{\mathrm{SSA}}=\left(v_{x}, v_{y}\right)\end{array}$ & $\mathrm{m} \mathrm{s}^{-1}$ & \\
\hline$v_{\text {SIA }}$ & SIA-modeled velocity of ice & $\mathrm{ms}^{-1}$ & \\
\hline$v_{\text {SSA }}$ & $\begin{array}{l}\text { SSA-modeled velocity of ice; } \\
\boldsymbol{v}_{\mathrm{SSA}}=\left(v_{x}, v_{y}\right)\end{array}$ & $\mathrm{ms}^{-1}$ & \\
\hline$(x, y)$ & horizontal dimensions & $\mathrm{m}$ & \\
\hline$z$ & $\begin{array}{l}\text { vertical dimension } \\
\text { (positive upwards) }\end{array}$ & $\mathrm{m}$ & \\
\hline$z_{\mathrm{b}}$ & elevation of the ice shelf base & $\mathrm{m}$ & \\
\hline$z_{\mathrm{sl}}$ & sea level & $\mathrm{m}$ & 0 \\
\hline$\beta_{\mathrm{CC}}$ & Clausius-Clapeyron gradient & $\mathrm{K} \mathrm{m}^{-1}$ & $8.66 \times 10^{-4}$ \\
\hline & thermal exchange velocity & $\mathrm{ms}^{-1}$ & $10^{-4}$ \\
\hline$\Delta x, \Delta y$ & horizontal grid size & $\mathrm{km}$ & 19.98 \\
\hline$\dot{\epsilon}_{ \pm}$ & $\begin{array}{l}\text { eigenvalues of horizontal strain } \\
\text { rate tensor }\end{array}$ & $\mathrm{s}^{-1}$ & \\
\hline$\lambda$ & $\begin{array}{l}\text { parameter for water content } \\
\text { in till }\end{array}$ & & \\
\hline$\rho_{\mathrm{i}}$ & density of ice & $\mathrm{kg} \mathrm{m}^{-3}$ & 910 \\
\hline$\rho_{\mathrm{o}}$ & density of ocean water & $\mathrm{kg} \mathrm{m}^{-3}$ & 1028 \\
\hline$\tau_{\mathrm{b}}$ & basal shear stress on ice & $\mathrm{Pa}=\mathrm{N} \mathrm{m}^{-2}$ & \\
\hline$\tau_{\mathrm{c}}$ & yield stress & $\mathrm{Pa}=\mathrm{N} \mathrm{m}^{-2}$ & \\
\hline$\tau_{i j}$ & $\begin{array}{l}\text { deviatoric stress tensor; } \\
\tau_{i j}=2 v \dot{\epsilon}_{i j}\end{array}$ & $\mathrm{~Pa}=\mathrm{Nm}^{-2}$ & \\
\hline$\phi$ & till friction angle & $\circ$ & \\
\hline$|\Phi|$ & latitude & ${ }^{\circ} \mathrm{S}$ & \\
\hline
\end{tabular}

are too numerous in the simulation, but the strongest overestimation occurs only in a small number of grid cells. For grounded grid cells the model gives more realistic values (see also Fig. 14).

\section{Conclusions}

Our dynamic equilibrium simulation for Antarctica demonstrates the ability of PISM-PIK to reproduce large-scale dynamic features of the Antarctic ice sheet-shelf system, including observed features such as the fast flow of ice streams and the position of ice fronts. A comparison of the geometry and dynamics in modeled equilibrium using observed surface velocities covering $\approx 65 \%$ of the ice-covered area supports the PISM-PIK treatment of the calving front and its direct superposition of SIA and SSA. These new techniques capture the full range of fast-flowing ice in the whole sheet/shelf system. This hybrid scheme leads to a smooth transition from sheet to shelves and permits a diagnostic definition of streams (Fig. 2). The mass budget of Antarctica in simulated steady state was analyzed, identifying the composition of mass loss at different types of ice fronts (Fig. 9). Though subgrid interpolation is used in PISM-PIK for the floating parts of the calving front (Albrecht et al., 2011), it is currently not used for locations where the model has grounded ice margins. This may be the explanation for a reduced area of floating ice in the model relative to observations (Table 1). The formation of an attached shelf influences the grounded ice upstream, both by buttressing effects in the case of an embayment and the draw-down of grounded ice because of high shelf velocities being transmitted by membrane stresses into the upstream grounded ice. Additional subgrid treatment may improve grounded marine margins in future model versions. Significant additional improvements, particularly with respect to grounding line position (Fig. 6), ice thickness distribution (Fig. 7), and velocity distribution (Figs. 10-16), are expected from finer grid resolution, improved topographic input data, and additional information on the dynamic basal boundary conditions (basal shear stress) of grounded ice.

\section{Supplementary material related to this article is available online at: http://www.the-cryosphere.net/5/727/2011/ tc-5-727-2011-supplement.zip.}

Acknowledgements. M. Haseloff and T. Albrecht were funded by the German National Academic Foundation; M. A. Martin and R. Winkelmann by the TIPI project of the WGL. R. Winkelmann acknowledges support by the IMPRS-ESM. E. Bueler and C. Khroulev are supported by NASA grant NNX09AJ38G. We thank Jed Brown (ETH Zurich, Switzerland) for advice on PISM, and the anonymous referees and editor Hilmar Gudmundsson for their helpful comments on the original manuscript.

Edited by: G. H. Gudmundsson 


\section{References}

Albrecht, T., Martin, M., Haseloff, M., Winkelmann, R., and Levermann, A.: Parameterization for subgrid-scale motion of ice-shelf calving fronts, The Cryosphere, 5, 35-44, doi:10.5194/tc-5-352011, 2011.

Arthern, R. J. and Gudmundsson, G. H.: Initialization of ice-sheet forecasts viewed as an inverse Robin problem, J. Glaciol., 56, 527-533, 2010.

Bamber, J. L., Vaughan, D. G., and Joughin, I.: Widespread Complex Flow in the Interior of the Antarctic Ice Sheet, Science, 287, 1248-1250, 2000.

Beckmann, A. and Goosse, H.: A parametrization of ice shelf-ocean interaction for climate models, Ocean Model., 5(2), 157-170, 2003.

Bueler, E. and Brown, J.: The shallow shelf approximation as a sliding law in a thermomechanically coupled ice sheet model, J. Geophys. Res., 114, F03008, doi:10.1029/2008JF001179, 2009.

Bueler, E., Brown, J., and Lingle, C.: Exact solutions to the thermomechanically coupled shallow-ice approximation: effective tools for verification, J. Glaciol., 53, 499-516, 2007.

Bueler, E., Khroulev, C., Aschwanden, A., Joughin, I., and Smith, B. E.: Modeled and Observed Fast Flow in the Greenland Ice Sheet, 2010.

Clarke, G. K. C.: Subglacial Processes, Annu. Rev. Earth Pl. Sc., 33, 247-276, 2005.

Comiso, J. C.: Variability and Trends in Antarctic Surface Temperatures from In Situ and Satellite Infrared Measurements, J. Climate, 13, 1674-1696, 2000.

Goldberg, D. N. and Sergienko, O. V.: Data assimilation using a hybrid ice flow model, The Cryosphere, 5, 315-327, doi:10.5194/tc-5-315-2011, 2011.

Hellmer, H. H. and Olbers, D. J.: A Two-Dimensional Model for the Thermohaline Circulation Under an Ice Shelf, Antarct. Sci., 1(04), 325-336, 1989.

Holland, D. M. and Jenkins, A.: Modeling Thermodynamic IceOcean Interactions at the Base of an Ice Shelf, J. Climate, 29, 1787-1800, 1999.

Hulbe, C. L. and MacAyeal, D. R.: A new numerical model of coupled inland ice sheet, ice stream, and ice shelf flow and its application to the West Antarctic Ice Sheet, J. Geophys. Res., 104, 25349-25366, 1999.

Huybrechts, P.: A 3-D model for the Antarctic ice-sheet: a sensitivity study on the glacial-interglacial contrast, Clim. Dynam., 5, 79-92, 1990.

Huybrechts, P.: Glaciological modellint of the late Cenozoic East Antarctic Ice Sheet: Stability or dynamism, Geogr. Ann., 75A(4), 221-238, 1993.

Jezek, K. C., Farness, K., Carande, R., Wu, X., and LabelleHamer, N.: RADARSAT 1 synthetic aperture radar observations of Antarctica: Modified Antarctic Mapping Mission, 2000, Radio Sci., 38, 32-1, 2003.

Joughin, I., Tulaczyk, S., Bindschadler, R., and Price, S. F.: Changes in west Antarctic ice stream velocities: Observation and analysis, J. Geophys. Res.-Sol. Ea., 107, 2289 pp., EPM 3-1-322, 2002.

Joughin, I., Tulaczyk, S., Bamber, J., Blankenship, D., Holt, J., Scambos, T., and Vaughan, D.: Basal Conditions for Pine Island and Thwaites Glaciers Determined using Satellite and Airborne Data, J. Glaciology, 55(190), 245-257, 2009.
Le Brocq, A. M., Payne, A. J., and Vieli, A.: An improved Antarctic dataset for high resolution numerical ice sheet models (ALBMAP v1), Earth Syst. Sci. Data, 2, 247-260, doi:10.5194/essd-2-247-2010, 2010.

Levermann, A., Albrecht, T., Winkelmann, R., Martin, M. A., and Haseloff, M.: Universal Dynamic Calving Law implies Potential for Abrupt Ice-Shelf Retreat, submitted, 2011.

Liu, H., Jezek, K. C., and Li, B.: Development of an Antarctic digital elevation model by integrating cartographic and remotely sensed data: A geographic information system based approach, J. Geophys. Res., 104, 23199-23214, 1999.

Lythe, M. B., Vaughan, D. G., and BEDMAP Consortium: BEDMAP: A new ice thickness and subglacial topographic model of Antarctica, J. Geophys. Res., 106, 11335-11351, 2001.

Ma, Y., Gagliardini, O., Ritz, C., Gillet-Chaulet, F., Durand, G., and Montagnat, M.: Enhancement Factors for Grounded Ice and IceShelves inferred from an anisotropic ice flow model, J. Glaciol., 56, 805-812, 2010.

Macayeal, D. R.: The basal stress distribution of ice stream E, Antarctica, inferred by control methods, J. Geophys. Res., 97, 595-603, 1992.

MacAyeal, D. R.: A tutorial on the use of control methods in icesheet modeling, J. Glaciol., 39(131), 91-98, 1993.

Maxwell, D., Truffer, M., Avdonin, S., and Stuefer, M.: An iterative scheme for determining glacier velocities and stresses, J. Glaciol., 54, 888-898, 2008.

Oerter, H., Kipfstuhl, J., Determann, J., Miller, H., Wagenbach, D., Minikin, A., and Graft, W.: Evidence for basal marine ice in the Filchner-Ronne ice shelf, Nature, 358(6385), 399-401, 1992.

Paterson, W. S. B.: The Physics of Glaciers, Elsevier, Oxford, 1994.

Pollard, D. and Deconto, R. M.: Modelling West Antarctic ice sheet growth and collapse through the past five million years, Nature, 458, 329-332, 2009.

Pritchard, H. D., Arthern, R. J., Vaughan, D. G., and Edwards, L. A.: Extensive dynamic thinning on the margins of the Greenland and Antarctic ice sheets, Nature, 461, 971-975, 2009.

Raymond, M. J. and Gudmundsson, G. H.: Estimating basal properties of ice streams from surface measurements: a nonlinear Bayesian inverse approach applied to synthetic data, The Cryosphere, 3, 265-278, doi:10.5194/tc-3-265-2009, 2009.

Ritz, C., Rommelaere, V., and Dumas, C.: Modeling the evolution of Antarctic ice sheet over the last 420,000 years: Implications for altitude changes in the Vostok region, J. Geophys. Res., 106, 31943-31964, 2001.

Rott, H., Müller, F., Nagler, T., and Floricioiu, D.: The imbalance of glaciers after disintegration of Larsen-B ice shelf, Antarctic Peninsula, The Cryosphere, 5, 125-134, doi:10.5194/tc-5-1252011, 2011.

Schoof, C.: Variational methods for glacier flow over plastic till, J. Fluid Mech., 555(-1), 299-320, 2006a.

Schoof, C.: A variational approach to ice stream flow, J. Fluid Mech., 556, 227-251, 2006b.

Schoof, C., Hindmarsh, R. C. A., and Pattyn, F.: MISMIP: Marine ice sheet model intercomparison project, http://homepages.ulb. ac.be/ $\sim$ fpattyn/mismip/, 2009.

SeaRISE, Sea-level Response to Ice Sheet Evolution (SeaRISE), 2011.

Shapiro, N. M. and Ritzwoller, M. H.: Inferring surface heat flux distributions guided by a global seismic model: particular 
application to Antarctica, Earth Planet Sc. Lett., 223, 213-224, 2004.

Thomas, R., Rignot, E., Casassa, G., Kanagaratnam, P., Acuña, C., Akins, T., Brecher, H., Frederick, E., Gogineni, P., Krabill, W., Manizade, S., Ramamoorthy, H., Rivera, A., Russell, R., Sonntag, J., Swift, R., Yungel, J., and Zwally, J.: Accelerated SeaLevel Rise from West Antarctica, Science, 306, 255-258, 2004. Van de Berg, W. J., Van den Broeke, M. R., Reijmer, C. H., and Van Meijgaard, E.: Reassessment of the Antarctic surface mass balance using calibrated output of a regional atmospheric climate model, J. Geophys. Res.-Atmos., 111, D11104, doi:10.1029/2005JD006495, 2006.
Van den Broeke, M.: Depth and Density of the Antarctic Firn Layer, Arct. Antarct. Alp. Res., 40, 432-438, 2008.

Winkelmann, R., Martin, M. A., Haseloff, M., Albrecht, T., Bueler, E., Khroulev, C., and Levermann, A.: The Potsdam Parallel Ice Sheet Model (PISM-PIK) - Part 1: Model description, The Cryosphere, 5, 715-726, doi:10.5194/tc-5-715-2011 2011. 